\title{
O papel do livro didático na construção do letramento escolar
}

\author{
MARIA DO SOCORRO ALENCAR NUNES MACEDO*
}

\section{RESUMO}

Este trabalho discute alguns aspectos que constituem o letramento escolar em uma turma de final do primeiro ciclo, em que o livro didático é o elemento central. Os dados foram coletados em vídeo e o foco da análise são os processos interacionais, constituídos por alunos e professora em torno de um livro didático de português. Os resultados indicam que a professora dialoga com o livro didático, apropriando-se dessa ferramenta cultural de acordo com os dispositivos que constituem o seu fazer cotidiano. Nesse sentido, ela não reproduz e não segue linearmente a proposta pedagógica do livro, mas a modifica, ampliando e redimensionando as atividades propostas.

Palavras-chave: letramento, alfabetização, livro didático.

\section{RESUMEN}

Este trabajo discute algunos aspectos que constituyen el letramento escolar en un grupo que está terminando el primer ciclo y en el que el libro didáctico es el elemento central. Los datos fueron registrados en video y el análisis se centra en los procesos interactivos constituídos por alumnos y profesores en torno a un libro didáctico de portugués. Los resultados indican que la profesora dialoga con el libro didáctico, apropiándose de esta herramienta cultural de acuerdo con los dispositivos que constituyen el quehacer cotidiano. En este sentido, no reproduce y

\footnotetext{
* Professora do Programa de Pós-Graduação em Educação da Universidade Federal de São João del Rei - UFSJ (socorronunes@ufsj.edu.br).
} 
no sigue linealmente la propuesta pedagógica del libro, sino que la modifica, ampliando y redimensionando las actividades propuestas.

Palabras clave: letramento, alfabetización, libro didáctico.

\section{ABSTRACT}

This paper discusses some aspects that constitute school literacy in an elementary school. It focuses on classroom interactions mediated by a Portuguese textbook. The data were collected through video recordings. The findings indicate that the teacher doesn't reproduce the textbook's proposal but she appropriates of that in a creative way, adding new activities according to the way she organizes her pedagogic practice in the classroom.

Keywords: school literacy, textbook. 
Este trabalho discute alguns aspectos que constituem o letramento escolar em uma turma de final do primeiro ciclo, em que o livro didático é o elemento central. $\mathrm{O}$ foco da análise são os processos interacionais constituídos por alunos e professora em torno de um livro didático de português. Algumas questóes que guiam as análises são: como se configuram as interaçôes mediadas pelo livro didático? Como o discurso é construído nesse espaço interacional? Que vozes o livro didático faz circular nesse espaço? Como a professora apropria-se desse instrumento na sua prática pedagógica?

Consideramos que a professora dialoga com o livro didático, apropriando-se dessa ferramenta cultural de acordo com os dispositivos que constituem o seu fazer cotidiano. Nesse sentido, ela não reproduz e não segue linearmente a proposta pedagógica do livro, mas a modifica, ampliando-a e redimensionando as atividades propostas.

A perspectiva teórico-metodológica que suporta a pesquisa articula conceitos da teoria da enunciação de Bakhtin $(1981 ; 1995)$, a concepçáo de letramento como prática sociocultural (Street, 1984; Heath, 1983) e conceitos de pesquisadores etnógrafos que estudaram interaçóes em sala de aula (Mehan, 1979; Collins; Green, 1992).

Bakhtin (1995) postula que a interação verbal, de natureza dialógica e social, é a categoria básica da concepção de linguagem como um fenômeno social, marcado ideologicamente. Disso decorre que o enunciado é a unidade de análise dos processos de interação verbal, "a verdadeira unidade da comunicaçáo verbal". Para Bakhtin, o diálogo, concebido como um processo que ultrapassa a interação face a face, é o traço fundamental do enunciado e da enunciação. O livro didático, nessa perspectiva, pode ser visto como um enunciado que se constitui em elo na cadeia de "comunicação verbal" estabelecida por alunos e professora na sala de aula. A análise das interaçóes face a face, que constituem o uso do livro didático, pode ser fecunda para a compreensáo dos processos de letramento escolar (Macedo; Mortimer; Green, 2004).

Pesquisadores têm investigado as interaçóes em sala de aula partindo do pressuposto que essa é uma "comunidade culturalmente constituída" por meio da participação de diferentes sujeitos, que assumem diferentes papéis no processo de ensinoaprendizagem (Collins; Green, 1992). Nessa perspectiva, a aprendizagem é definida situacionalmente por meio das formas em que professores e alunos constroem os padróes e práticas da vida de cada sala de aula. Vista dessa forma, a sala de aula é um espaço no qual um grupo constrói e reconstrói uma "cultura de sala" com base em uma "cultura escolar". 
O conceito de letramento é muito complexo e tem sido definido de muitas formas. No Brasil vem sendo debatido desde os anos 90 por pesquisadores como Kleiman (1995) e Soares (1998) com uma influência clara da formulação proposta por Street (1984), que afirma:

Eu usarei o termo letramento para nomear as práticas sociais e as concepçóes de leitura e escrita [...]. O que as práticas particulares e os conceitos de leitura e escrita são para uma dada sociedade depende do contexto. (p.1)

Pesquisadores da etnografia interacional têm enfatizado o uso da palavra no plural, tendo por objetivo tornar visível a dimensão multifacetada e plural das práticas sociais de leitura e escrita. De acordo com essa abordagem, para se compreender os processos de letramento, é fundamental analisar "os processos comunicativos através dos quais ele é construído" (p.121). Nesse sentido, este texto discute elementos constitutivos dos processos de letramento na sala de aula, focalizando as interaçóes discursivas que ocorrem entre alunos e professora quando um livro didático está sendo usado.

\section{METODOLOGIA}

Os dados analisados foram coletados em vídeo numa turma de primeiro ciclo da Rede Municipal de Belo Horizonte. A escola está localizada na periferia da cidade e atende a uma clientela considerada de baixa renda. Foram gravadas 38 horas, durante o primeiro semestre do ano letivo, desde o primeiro dia de aula. No primeiro mês, a gravaçáo era feita diariamente nas aulas ocorridas antes do recreio; e nos meses subsequentes, em média, três dias por semana. A maior parte dos dados constitui-se de aulas em que o uso do livro didático foi central. Além disso, foi feita uma entrevista com a professora em que pudemos coletar informaçóes relacionadas aos dados em vídeo e à sua prática pedagógica de maneira geral. Além de gravaçóes em vídeo, aplicamos um questionário a todos os professores do primeiro ciclo dessa rede de ensino, com perguntas relacionadas às formas de organização das interaçôes em sala de aula e ao uso do livro didático no ensino da leitura e da escrita.

Os dados da sala de aula foram representados em mapas de eventos, instrumento usado por pesquisadores da etnografia interacional que pode ser definido como uma transcrição ou representação de um evento, um ciclo de atividades ou um segmento da história de um grupo, construída pelos sujeitos por meio do processo dialógico e interacional (Green; Meyer, 1991). Um aspecto que pode ser comum a todos os mapas é o fato de representarem como o tempo foi gasto, e como o espaço 
foi utilizado pelos participantes. Após o mapeamento dos eventos e a identificação daqueles a serem analisados, selecionamos sequências discursivas consideradas representativas da dinâmica discursiva da sala de aula.

As estratégias de pesquisa que guiaram a coleta, a organização e a análise dos dados buscaram a construçáo de uma perspectiva que nos permitiu contrastar dados do discurso da professora com os da sua prática pedagógica. Como afirma Spradley (1980), "os significados de cada domínio cultural vêm das diferenças, assim como das similaridades [...]. Qualquer questáo sobre diferenças é uma questão de contraste" (p.125). Para Green, Dixon e Zaharlick (2001), o "contraste é a base para triangulação de perspectivas, dados, método e teoria” (p.208).

\section{RESULTADOS}

Apresentamos três níveis de análise: o primeiro refere-se aos dados do questionário que indicam, por meio do discurso das professoras, como o livro didático é concebido e usado em sala de aula; no segundo, elaboramos, com base nos dados em vídeo, um mapeamento das práticas de letramento construídas nas aulas filmadas; no terceiro, mais refinado, analisamos, em uma das aulas consideradas representativas, as interaçóes desenvolvidas nas práticas de letramento, quando o livro didático estava sendo utilizado.

\section{$1 \mathrm{O}$ discurso das professoras sobre o uso do livro didático}

Por meio de um questionário aplicado a todos os professores do primeiro ciclo da Rede Municipal de Belo Horizonte, pudemos observar aspectos do discurso das professoras referente ao uso do LD. A grande maioria (77,3\%) afirma usar o LD no primeiro ciclo. Somente $20 \%$ não usam esse recurso e $2,7 \%$ não responderam à pergunta. Considerando que a proposta político-pedagógica "Escola Plural da Rede Municipal" náo enfatiza o uso do livro didático, é surpreendente a quantidade de professoras que diz usar esse material. Essa é uma evidência de que as docentes do primeiro ciclo dessa rede de ensino náo abandonaram o livro didático. No entanto, cabe-nos perguntar: como esse livro é usado em sala de aula? Com que frequência? Além do livro didático, que outros materiais são usados na construção das práticas de letramento da turma?

Sobre a frequência de uso do $\mathrm{LD}$, os dados do questionário são bastante reveladores. Somente 3\% das professoras assumem usá-lo diariamente, contrariando as expectativas construídas em torno da elaboração e do uso desse material. O modelo 
adotado pelo Ministério da Educação supôe o uso sequencial das atividades, pois os LDs são subdivididos em unidades temáticas, ou de conteúdos, calculadas para serem trabalhadas durante o ano letivo. A organização sequencial dos conteúdos é um dos critérios utilizados na avaliação dos livros pelo Programa Nacional do Livro Didático (PNLD). Os dados indicam, entretanto, que a maioria delas usa o LD alguns dias na semana (39,8\%), e 18,5\% o fazem ocasionalmente. Apenas 20,8\% nunca utilizam o LD. Esse número, somado ao que raramente faz uso dele (7,9\%), totaliza $28,7 \%$.

Tabela 1 - Frequência de uso do livro didático

\begin{tabular}{lrr}
\hline \multicolumn{1}{c}{ Frequência } & N & $\%$ \\
\hline Alguns dias na semana & 211 & 39,9 \\
Uma vez por semana & 31 & 5,9 \\
Ocasionalmente & 98 & 18,5 \\
Raramente & 42 & 7,9 \\
Todos os dias & 16 & 3,0 \\
Nunca & 110 & 20,8 \\
Não indicou & 21 & 4,0 \\
\hline TOTAL & 529 & 100,0 \\
\hline
\end{tabular}

Ao especificar qual(is) livro(s) didático(s) utilizam, a maioria das professoras $(69,7 \%)$ citou mais de um LD, argumentando que usa diferentes livros como material de pesquisa. O grupo que usa apenas um LD corresponde a 30,3\%.

Os dados acima indicam que as professoras do primeiro ciclo estão rompendo com um discurso pedagógico de negação do uso do livro didático, instituído nos anos 80. Entretanto, o fato de elas assumirem usar outros impressos, permite-nos supor que o LD, no primeiro ciclo da Rede Municipal de Belo Horizonte, perdeu a centralidade que tinha até os anos 80 , quando as cartilhas de alfabetização, baseadas em diferentes métodos de ensino da leitura e da escrita, eram utilizadas quase exclusivamente. Atualmente, após a implantação do PNLD, as cartilhas convencionais foram substituídas pelos chamados "Livros de Alfabetização", que refletem referenciais teórico-metodológicos bastante distintos daqueles apresentados nas cartilhas. Tais livros se caracterizam por uma concepção de língua como interação, como um objeto social e cultural que permite diferentes usos e tem diferentes funçóes sociais. O texto, e não a sílaba ou o fonema, é o ponto de partida para o ensino e a aprendizagem da leitura e da escrita. 
A maioria das professoras $(93,2 \%)$ afirma usar diferentes tipos de materiais para alfabetizar, e um grupo significativo $(77,3 \%)$ os utiliza articulados. Apenas $6,8 \%$ não indicaram outros materiais, mas isso não significa que usem apenas o LD. Ao contrário, nenhuma professora assumiu que utiliza apenas esse recurso. As professoras citaram uma diversidade significativa de impressos, que vão desde aqueles de circulação social até materiais pedagógicos produzidos pelas professoras e pelos alunos. Estão incluídas, também, atividades e estratégias pedagógicas não relacionadas à língua escrita, mas a outras linguagens. Essa diversidade evidencia a complexidade do material didático utilizado pelas professoras, dificultando sua categorização. Apresentamos a seguir uma tentativa de agrupamento, em que se tomou como critério o espaço social de circulaçáo e o suporte dos materiais.

- Impressos de circulação social: jornais, revistas, encartes de propaganda, catálogos, rótulos, quadrinhos, panfletos, receitas, contas de água, luz, telefone, livros de literatura infantil, etc.

- Materiais pedagógicos produzidos pela/na escola: cartazes, textos de alunos, fichas, painéis.

- Materiais pedagógicos específicos para a aquisição do sistema de escrita: letras móveis, jogos silábicos, fichas com nomes dos alunos, exercícios fotocopiados/mimeografados, sílabas móveis, etc.

Esses dados parecem relacionar-se, dentre outros fatores, ao discurso pedagógico de negação do LD bastante difundido a partir de meados da década de 80, após a divulgação das teorias construtivistas no campo da alfabetização, especialmente o trabalho de Ferreiro (1993). Atualmente, desdobramentos da discussão do conceito de letramento (Kleiman, 1995; Soares, 1998), muito divulgado em cursos de formação continuada da Rede Municipal de Belo Horizonte, têm apontado o uso exclusivo do LD como recurso restrito para a formação dos alunos na perspectiva do letramento.

\section{Caracterização geral das práticas de letramento nas aulas filmadas}

Como se caracterizam as práticas de letramento nessa turma? Que açóes mais frequentes envolveram a leitura e a escrita? A fim de estabelecer uma visão geral dessas práticas, elaborei um mapeamento das açóes dos participantes que envolveram a leitura e a escrita, após os eventos iniciais das aulas, tomando por base 38 horas de gravação em vídeo, distribuídas em 37 dias de filmagem no decorrer do primeiro semestre de 2001. 
Diferentes aspectos que constituíram as práticas de letramento da turma foram evidenciados. Destacamos, na análise, os materiais impressos que circularam nas aulas, as atividades e as práticas de letramento predominantes em cada aula. Em relação aos materiais impressos, podemos categorizá-los em três grupos, com base na proposta de Batista (1999): 1) texto impresso no suporte livro destinado ao aluno, tendo por objetivo servir de base para o ensino e a aprendizagem de um conteúdo de Língua Portuguesa, modelo de texto didático adotado pelo PNLD; 2) textos e impressos veiculados em outros suportes, como, por exemplo, folhas mimeografadas, cartazes, jogos, textos produzidos pelos alunos, etc.; 3) textos "paradidáticos" que circulam na escola, mas que não são destinados apenas a ela. É o caso dos livros de literatura infanto-juvenil, que apresentam um estatuto ambíguo. Apesar de a instituição escolar ser o destino preferencial, tais livros também são voltados ao mercado não escolar. A categoria "paraescolares" ou "paradidáticos" é a que mais se aproxima desse material.

Predominam aulas em que a leitura foi o objeto central, perfazendo um total de 17. Em segundo lugar, vem a ênfase na produção de textos, num total de 13 aulas. A análise da ortografia e de conceitos gramaticais aparece em seguida, correspondendo respectivamente a 12 e 2 aulas. Apenas em uma das aulas pôde-se observar atividades de caligrafia.

As práticas de leitura são diversificadas, não só em relação ao que se lê, mas também a como se lê e para que se lê. Podemos caracterizá-las subdividindo-as em dois grupos: leitura não sistemática e leitura sistemática. As práticas de leitura não sistemáticas, nomeadas por Albuquerque (2002) como "leitura livre" e identificadas também por Araújo (1999), ocorrem no momento em que os alunos podem escolher livros, na caixa de livros de literatura, e revistas em quadrinhos disponibilizados pela professora. Em razão dos limites deste artigo, focalizamos as análises apenas nas práticas sistemáticas de leitura e produção de textos, pois se caracterizam, prioritariamente, como práticas de letramento mediadas pelo livro didático.

\subsection{Práticas de leitura e produção mediadas pelo livro didático}

Como demonstrado anteriormente, duas "fontes" principais de textos estruturam as práticas de leitura da turma: textos do livro didático e textos mimeografados, preparados pelo grupo de professoras do primeiro ciclo.

Os textos mimeografados, usados em três aulas, trataram, prioritariamente, de conteúdos ligados às aulas de ciências e geografia. Com exceção do texto sobre a Terra, os demais são narrativas de cunho informativo, construídas com o propósito de transmitir informaçóes sobre algum conceito. São textos comumente encontrados em 
livros didáticos, portanto são textos "escolarizados" (Soares, 1999) que circulam prioritariamente na escola, o que caracteriza uma das dimensóes do letramento escolar.

A entrada do LD na sala de aula impulsiona a diversificação nas práticas de leitura do grupo em relaçáo ao que se lê. Esse impresso foi utilizado em $52 \%$ das aulas filmadas a partir de 21 de fevereiro, quando o livro passa a ser utilizado. $O$ que os alunos leram? Diferentes textos. Leram o primeiro texto dirigido a eles: a Carta de Apresentação da autora. Além disso, leram o sumário e, na Unidade 1, um texto informativo, de caráter enciclopédico, sobre o Carnaval, e dois textos sobre a vida de Mozart. $\mathrm{Na}$ Unidade 2, leram exemplos de propaganda e de placas de sinalização de trânsito, incluídos na seção Imagens. Também foi lida uma narrativa literária da Unidade 3 e uma poesia. $\mathrm{Na}$ Unidade 6, leram instruções de brincadeiras e uma narrativa literária.

O que esses dados nos indicam em relação ao papel do livro didático na estruturação das práticas de letramento e das interações nessa sala de aula? Se considerarmos a variedade de textos do livro didático lidos pelos alunos, em contraste com os textos mimeografados propostos pela professora, a diversidade é maior nas práticas de leitura propostas pelo LD.

A forma como eles foram lidos obedece a uma sequência não proposta explicitamente pelo livro didático, características das práticas de letramento do primeiro ciclo, conforme constatado também por Araújo (1999) e Albuquerque (2002), quais sejam: leitura silenciosa, leitura oral dos alunos, interpretação oral e escrita do texto e produção de texto. Observou-se que essas formas de leitura são recorrentes em quase todas as aulas e, em todas elas, a professora escolhe quem vai ler oralmente, que, no caso dessa turma, é sempre individual. Uma exceçáo ocorreu no dia 18 de maio, quando os meninos, separados das meninas, leram um poema proposto no livro. Nesse caso, o próprio texto talvez tenha motivado a alteraçáo no padrão de leitura da turma: apenas nesse dia a própria professora leu o texto, para marcar o ritmo e a entonaçáo. A leitura dos exercícios do livro é predominantemente oral e individual.

Não se observou uma discussão, com os alunos, da função da leitura silenciosa e da leitura oral dos textos, ou mesmo uma orientação mais específica sobre como cada texto pode ser lido. Os alunos constroem a expectativa de que a leitura tem por objetivo responder oralmente ou por escrito a perguntas previstas pelo LD ou propostas pela professora, o que poderia indicar uma concepção de leitura como decodificação, repetição, e não como compreensão, construção de sentidos pelo leitor na interação com o texto.

Assim como os textos lidos, os textos produzidos pelos alunos podem ser organizados em duas categorias. No primeiro conjunto, identificamos: 1) textos não 
vinculados ao LD de português, num total de sete; 2) textos propostos pelo LD, perfazendo um total de seis. Em relação à frequência com que ocorreram, as práticas de produçóes de textos concentraram-se, prioritariamente, nos meses de fevereiro e março, observando-se uma intensidade de produçóes nos primeiros três dias de aula (5, 6 e 7/2) e uma concentração significativa em março. Das aulas gravadas em abril, maio e junho, encontramos apenas uma atividade de produção de textos em cada mês, duas delas vinculadas ao LD.

Os textos caracterizaram-se por produçôes individuais, com temáticas bem específicas. Nos primeiros dias de aula, os temas foram As férias e Boas Vindas. Somente no primeiro dia de uso do LD (aula de 21/2), os alunos voltaram a escrever textos, nesse caso, uma música de carnaval a ser analisada no final da aula. A partir de então, a maior parte dos textos produzidos está vinculada ao $\mathrm{LD}$, com exceção das aulas dos dias 14 , 22 e $27 / 3$ e a aula de 4/6, ou seja, dos nove textos produzidos a partir da utilizaçáo do $\mathrm{LD}$, cinco são vinculados ao livro e quatro foram propostos pela professora em aulas de ciências e geografia. Os textos produzidos a partir do livro didático foram: uma música de carnaval que os alunos conheciam, uma propaganda, uma lista de nomes das pessoas da foto, uma narrativa com base em uma gravura e uma página de um diário. São textos diversificados, mas não foi explicitado, pela professora ou pelo livro didático, para quem os alunos estariam escrevendo e com qual objetivo. O LD, portanto, cumpriu o papel de estruturar as práticas de escrita de textos na maior parte das "aulas de português" e condicionar o que conta como letramento nessa sala de aula.

Um aspecto importante que caracteriza as práticas de produção de textos nessa sala de aula diz respeito à elaboração de textos coletivos, em detrimento de produçôes individuais, prática bastante difundida no primeiro ciclo depois da divulgação dos trabalhos de Ferreiro e Teberosky (1991) sobre a psicogênese da língua escrita. Das aulas gravadas, sete textos foram escritos coletivamente e seis individualmente. Dentre esses, um deles foi corrigido coletivamente pela turma (aula de 13/3). A prática de corrigir coletivamente os textos individuais é uma prática de letramento construída pelo grupo nesses dois anos de trabalho conjunto. Mesmo as produções escritas individualmente pelos alunos foram compartilhadas pelo grupo, por meio da exposiçáo desses textos nos murais da sala de aula, como se observou com os textos de boas vindas (6/2), a música de carnaval (21/2) e a propaganda (2/3). O grupo de alunos e a professora foram os interlocutores privilegiados dessas produçóes, com exceçáo do bilhete coletivo escrito para os pais (aula de 4 de junho), o que caracteriza um dos aspectos do letramento escolar: os interlocutores dos textos produzidos restringem-se, na maioria das vezes, aos próprios alunos e ao professor. 
A seguir, apresento o último nível de análise, cujo foco é uma das aulas mediadas pelo livro didático, buscando identificar aspectos constitutivos da dialogia em sala de aula, materializada nas interaçóes discursivas entre professora e alunos.

\section{Interaçóes nas práticas de letramento mediadas pelo livro didático}

Essa aula é representativa do conjunto de aulas em que a professora expande e amplia a proposta do livro didático, reconstruindo-a com base em dispositivos inerentes ao seu "saber-fazer". O trecho do livro utilizado na aula corresponde ao texto e às atividades indicadas na transcrição a seguir:

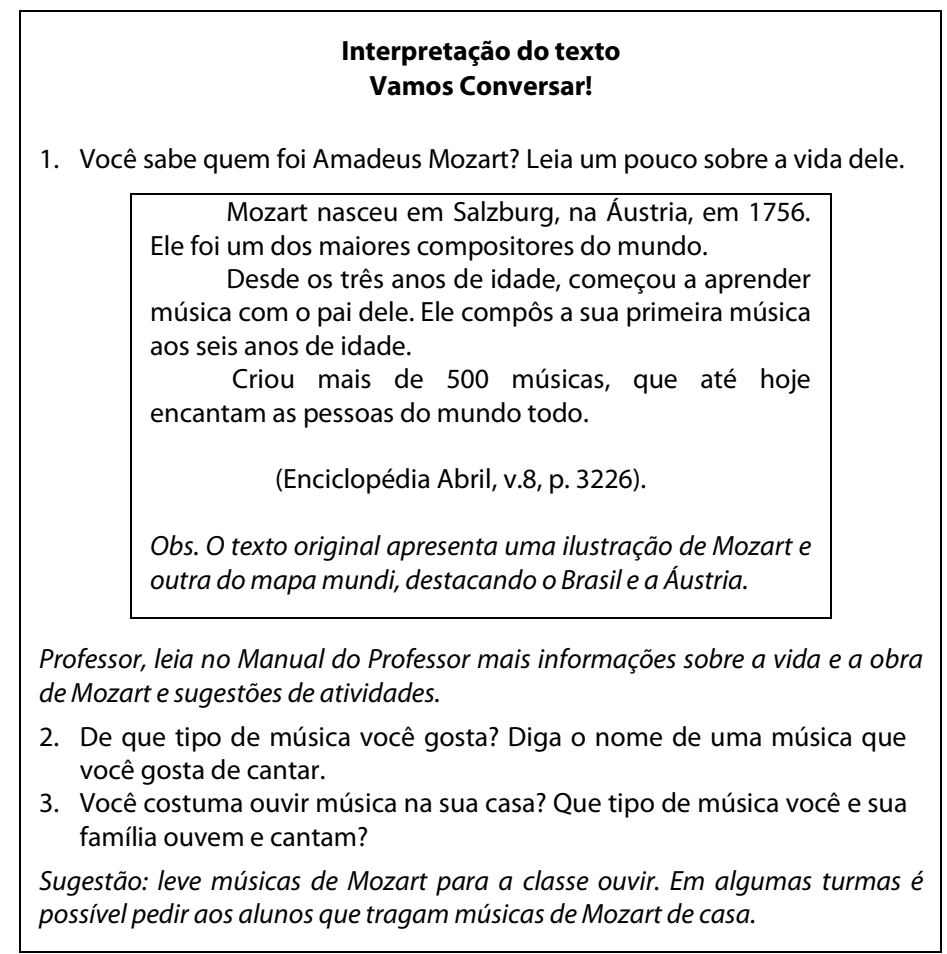

O evento de interação analisado neste tópico ocorreu em 16/3, quase um mês após o início do trabalho com o livro didático. No entanto, essa aula retoma a Unidade 1 do livro, páginas 2 e 3, seçôes: Leitura e Interpretação do Texto. Nesse ínterim, foi trabalhada com os alunos a Unidade 2, intitulada Imagens. A filmagem começa com os alunos já sentados em pequenos grupos, com o livro didático em mãos. São 81 minutos de gravação, organizados em quatro eventos, como se observa no quadro 1 . 


\section{Quadro 1 - "Tudo que vocês vão ver aqui é de faz-de-conta, mas o Mozart é de verdade"}

\begin{tabular}{|c|c|c|c|c|}
\hline Evento & $\begin{array}{l}\text { Tempo gasto } \\
\text { em minutos }\end{array}$ & $\begin{array}{l}\text { Linha de } \\
\text { tempo* }\end{array}$ & Ações dos participantes & $\begin{array}{c}\text { Comentários da pesquisadora / } \\
\text { aspectos extralinguísticos }\end{array}$ \\
\hline $\begin{array}{l}\text { Lendo e } \\
\text { discutindo a } \\
\text { vida de Mozart }\end{array}$ & 09 & 00:09: 04 & $\begin{array}{l}\text { Professora indica as páginas do } \\
\text { livro a serem lidas. } \\
\text { Professora relembra o texto lido } \\
\text { na aula anterior (p. } 2 \text { do livro). } \\
\text { Professora indica a leitura } \\
\text { silenciosa do texto sobre a vida } \\
\text { de Mozart. } \\
\text { Professora pergunta quem quer } \\
\text { fazer a leitura oral. Karina é } \\
\text { escolhida. } \\
\text { Karina termina a leitura. Inicia-se a } \\
\text { discussão do texto pela análise do } \\
\text { mapa que ilustra o texto. }\end{array}$ & $\begin{array}{l}\text { Enquanto isso, os alunos } \\
\text { devolvem os livros de literatura } \\
\text { emprestados da biblioteca. } \\
\text { Espera os alunos fazerem } \\
\text { silêncio. }\end{array}$ \\
\hline $\begin{array}{l}\text { Lendo um livro } \\
\text { literário sobre } \\
\text { Mozart }\end{array}$ & 13 & $\begin{array}{l}\text { 00:12: } 14 \\
\text { 00:13: } 14 \\
\text { 00:15: } 11\end{array}$ & $\begin{array}{l}\text { Termina a discussão. Professora } \\
\text { anuncia o livro de literatura que } \\
\text { será lido em seguida. } \\
\text { Professora convoca os alunos } \\
\text { para fazer a rodinha, onde } \\
\text { ocorrerá a leitura do livro. } \\
\text { Professora lê os aspectos } \\
\text { paratextuais do livro. } \\
\text { Leitura oral da professora, } \\
\text { entremeada de observações dos } \\
\text { alunos e dela própria. }\end{array}$ & $\begin{array}{l}\text { Mostra o livro aos alunos. } \\
\text { Eles demoram a se organizar na } \\
\text { rodinha. }\end{array}$ \\
\hline Merenda & 20 & & Intervalo & \\
\hline & 21 & $\begin{array}{l}00: 45: 24 \\
00: 66: 01\end{array}$ & $\begin{array}{l}\text { De volta à sala. Retomada da } \\
\text { leitura. } \\
\text { Término da leitura. }\end{array}$ & $\begin{array}{l}\text { Alunos demoram muito a se } \\
\text { reorganizarem na rodinha. } \\
\text { Muitos sentam-se nas mesas. }\end{array}$ \\
\hline $\begin{array}{l}\text { Ouvindo } \\
\text { músicas de } \\
\text { Mozart }\end{array}$ & 27 & $\begin{array}{l}\text { 00:68: } 06 \\
00: 71: 03 \\
\text { 00:81: } 03\end{array}$ & $\begin{array}{l}\text { Professora apresenta CDs aos } \\
\text { alunos e fala sobre sua obra. } \\
\text { Professora canta um trecho de } \\
\text { uma ópera de Mozart, a pedido } \\
\text { dos alunos. } \\
\text { Alunos ouvem músicas de } \\
\text { Mozart. } \\
\text { Recreio. }\end{array}$ & $\begin{array}{l}\text { Enquanto ouvem, dançam uns } \\
\text { com os outros. }\end{array}$ \\
\hline
\end{tabular}

*A linha de tempo não corresponde à "hora-relógio", pois foi marcada pelo programa C-Video. 
A análise do quadro evidencia alguns elementos das ações da turma nessa aula. Observa-se que as açóes foram realizadas a partir do livro didático, mas as atividades desenvolvidas não correspondem, efetivamente, ao que foi proposto pelo material. O livro propóe como atividade a leitura de um texto sobre Mozart e a discussáo das seguintes perguntas: 1. Diga o nome de uma música que você gosta de cantar; 2 . Você costuma ouvir música na sua casa? Que tipo de música você e sua família ouvem ou cantam? No livro do professor, há a sugestão de que ele peça aos alunos ou leve para a turma CDs de músicas do compositor para serem ouvidas em classe. No entanto, o que ocorreu na aula ultrapassou a proposta do livro, uma vez que outros recursos pedagógicos foram utilizados pela professora, tais como o livro de literatura e a sua participaçáo como cantora. Observando o tempo gasto em cada evento, percebe-se que, dos 81 minutos de gravaçáo, apenas 11 foram gastos com o uso do LD. O restante da aula (descontados os 20 minutos para a merenda) girou em torno da leitura do livro de literatura e das atividades de canto e de escuta de músicas do compositor.

É visível a diversidade das formas de uso do espaço da sala de aula e, consequentemente, das interaçóes ocorridas nessa aula. Os alunos iniciaram a aula organizados em pequenos grupos, e a leitura do livro de literatura é feita na rodinha, na frente da sala. A interação dos alunos muda sensivelmente, pois o objetivo desse modo de organização é sentar no chão para ouvir, de forma descontraída, a leitura da professora. Após o intervalo da merenda, a rodinha perde a centralidade, e boa parte dos alunos continua a ouvir a leitura sentados em suas carteiras. Com o término da leitura, todos voltam aos pequenos grupos para ouvir as músicas de Mozart e o canto da professora. Ao ouvir as músicas, muitos alunos se levantam e começam a dançar individualmente, e alguns em duplas. Essa diversidade de açóes evidencia a imprevisibilidade nas formas de organização e na interação da turma nessa aula. Nenhuma dessas formas de organização foi prevista e/ou proposta pelo livro didático, ou anunciada pela professora. Elas refletem expectativas já construídas, pela turma, nos dois anos de convivência: como construírem coletivamente o uso do espaço para realizarem as atividades propostas pela professora (Green; Wallat, 1981).

O quadro 1 confirma aspectos regulares da dinâmica do trabalho com a leitura, já discutidos anteriormente. As atividades de leitura, nessa aula, priorizam dois procedimentos: leitura silenciosa e leitura oral, quase sempre realizados nessa sequência, como mostramos na aula de 21/2.

A seguir, analiso um trecho da sequência discursiva em que a leitura do texto do livro didático ocorreu. Essa sequência nos ajuda a compreender melhor como as interaçóes e práticas de letramento são constituídas em torno do livro didático. Ela inicia-se quando os alunos terminam de fazer a leitura silenciosa do texto e se preparam para a leitura oral. 
Quadro 2 - Discutindo sobre a vida de Mozart

\begin{tabular}{|c|c|c|c|}
\hline Turnos & Participantes & Discurso & $\begin{array}{l}\text { Comentários da pesquisadora / } \\
\text { aspectos extralinguísticos }\end{array}$ \\
\hline 30 & Alunos & Acabei! Acabei! Pronto Mara! & \\
\hline 31 & Professora & Pronto, pronto! Quem quer ler? & Muitos alunos levantam a mão. \\
\hline 32 & Aluna & Começa daqui. & $\begin{array}{l}\text { Refere-se à direção que a professora } \\
\text { deve seguir pra escolher os alunos } \\
\text { que vão ler. }\end{array}$ \\
\hline 33 & Professora & $\begin{array}{l}\text { Ah! Hoje é daqui, né? Então Karina lê pra nós } \\
\text { depois. }\end{array}$ & $\begin{array}{l}\text { Refere-se ao grupo do canto direito } \\
\text { da sala. É uma regra instituída nos } \\
\text { anos anteriores. }\end{array}$ \\
\hline 34 & Karina & A número 1? & \\
\hline 35 & Professora & Número 1. & \\
\hline 36 & Karina & $\begin{array}{l}\text { Você sabe quem foi Amadeu Mozart? Leia um } \\
\text { pouco sobre a vida dele. Mozart nasceu (...) }\end{array}$ & $\begin{array}{l}\text { Os colegas não escutam, a } \\
\text { professora pede silêncio. }\end{array}$ \\
\hline 37 & Professora & $\begin{array}{l}\text { Peraí, gente! Não tô escutando a Karina, pode ler } \\
\text { mais alto um pouquinho? (incompreensível). Vai. }\end{array}$ & \\
\hline 38 & Karina & Mozart nasceu em Salzburgo na AusTRIA em (...) & \\
\hline 39 & Professora & ÁUStria. Mil setecentos (+) & $\begin{array}{l}\text { Corrige a pronúncia da aluna e lê a } \\
\text { data. }\end{array}$ \\
\hline 40 & Karina & Cinquenta e seis. & \\
\hline 41 & Professora & Isso! & \\
\hline 42 & Karina & $\begin{array}{l}\text { Ele foi um dos maiores compositores do mundo. } \\
\text { Desde os três anos de idade começou a aprender } \\
\text { música com o pai dele. Ele compôs a sua primeira } \\
\text { música aos seis anos de idade. Criou mais de } 500 \\
\text { músicas, que até hoje encantam as pessoas do } \\
\text { mundo todo. }\end{array}$ & \\
\hline 43 & Professora & $\begin{array}{l}\text { Isso! Muito bem! Oh, gente, então Mozart nasceu } \\
\text { em Salzburg lá na Áustria. Olha no mapa aí? Tá } \\
\text { vendo o Brasil, em vermelho aí? }\end{array}$ & Refere-se à ilustração do texto. \\
\hline 44 & Aluno & Estou! & \\
\hline 45 & Professora & $\begin{array}{l}\text { Não, porque o mapa é pequeno. Acha a Áustria, } \\
\text { gente. Tá de vermelho, lá, bem pequenininho, lá } \\
\text { na ponta. }\end{array}$ & \\
\hline 46 & Alunos & Aqui! Aqui! & \\
\hline 47 & Professora & $\begin{array}{l}\text { Hã, hã. É lá que o Mozart nasceu, na cidade } \\
\text { chamada Salzburg, né, Karina? Salzburg. Tá escrito } \\
\text { aí. Cê num leu, não? Como eu falei pra vocês, ele } \\
\text { foi um dos maiores compositores do mundo, mas } \\
\text { isso há muito tempo atrás. Vocês acham que a } \\
\text { Áustria é longe do Brasil? }\end{array}$ & \\
\hline 48 & Alunos & É. & \\
\hline 49 & Professora & Bastante, né? Que que tem no meio? & Refere-se ao mapa. \\
\hline 50 & Aluno & Tem que ir de avião. & \\
\hline 51 & Professora & Tem. & \\
\hline 52 & Aluna & No meio tem a água. & \\
\hline 53 & Professora & Tem água. Do mar, não é? & \\
\hline 54 & Aluno & Tem que pegar avião. & \\
\hline 55 & Professora & Ou navio, né, que demora mais ainda. É longe sim. & \\
\hline
\end{tabular}




\begin{tabular}{|c|c|c|c|}
\hline Turnos & Participantes & Discurso & $\begin{array}{l}\text { Comentários da pesquisadora / } \\
\text { aspectos extralinguísticos }\end{array}$ \\
\hline 56 & Aluna & (incompreensível) Mas é longe! & \\
\hline 57 & Professora & É. & \\
\hline 58 & Aluno & Demora uns dez dias. & \\
\hline 59 & Professora & Depende de que. & Refere-se ao meio de transporte. \\
\hline 60 & Alunos & (incompreensível). & \\
\hline 61 & Professora & $\begin{array}{l}\text { Oh, AIARA, presta atenção na aula! Você também } \\
\text { JÚLIO. Tira esse negócio da boca! Gente, Mozart, } \\
\text { ele foi um gênio porque ele aprendeu a fazer } \\
\text { músicas com } 3 \text { aninhos de idade. É o que tá } \\
\text { falando aqui. }\end{array}$ & Aponta para o LD. \\
\hline 62 & Robert & Ele acreditava na lâmpada (incompreensível). & \\
\hline 63 & Professora & Não, Robert! Gênio no sentido de inteligente. & \\
\hline 64 & Aluno & (incompreensível). & \\
\hline 65 & Professora & $\begin{array}{l}\text { É, é porque ele era muito inteligente. O pai dele } \\
\text { era músico, ele começou }(. . .)\end{array}$ & \\
\hline 66 & Aluna & Esse aqui é ele também? & \\
\hline 67 & Professora & Esse? Essa é a foto dele com seis anos. & \\
\hline 68 & Aluna & Nossa! Parece uma menina! & \\
\hline 69 & Professora & $\begin{array}{l}\text { É, na época que ele viveu, na época que ele viveu, } \\
\text { todas as pessoas, até as crianças, usavam peruca } \\
\text { no cabelo. }\end{array}$ & \\
\hline 70 & Aluna & Por que, Mara? & \\
\hline 71 & Professora & $\begin{array}{l}\text { Era moda, lá na França (+) Olha aí. Tá vendo? A } \\
\text { roupa era assim. }\end{array}$ & \\
\hline 72 & Aluna & Aqui Mara (incompreensível). & \\
\hline 73 & Professora & A roupa era assim. & \\
\hline 74 & Aluno & (incompreensível) & \\
\hline 75 & Professora & $\begin{array}{l}\text { Pois é, olha a roupa era assim. Olha o rosto como } \\
\text { é que era. }\end{array}$ & \\
\hline 76 & Aluno & (incompreensível) & \\
\hline 77 & Professora & $\begin{array}{l}\text { Tá vendo? Com seis anos, ele fez a primeira } \\
\text { música dele. Mas com seis anos, gente, com sete, } \\
\text { ele já foi cantar pro rei, de tanto que ele já tocava } \\
\text { bem, viu? }\end{array}$ & \\
\hline 78 & Aluna & Mara, ele ganhava muito dinheiro? & \\
\hline 79 & Professora & Hã? & \\
\hline 80 & Aluno & Ele ganhava muito dinheiro? & \\
\hline 81 & Professora & $\begin{array}{l}\text { Ah! Isso, é isso que vocês vão descobrir agora, } \\
\text { porque eu achei uma coisa na biblioteca. }\end{array}$ & \\
\hline
\end{tabular}

No turno 30, os alunos indicam que terminaram a leitura silenciosa. A professora, na sequência, pergunta quem quer fazer a leitura oral. Quase todos os alunos levantam a mão em resposta à pergunta: "quem quer ler?” Essa pergunta é retórica, uma vez que 
a escolha do aluno que irá ler não depende de quem levantou a mão. A professora, frequentemente, é quem escolhe os alunos, usando como critério a localização espacial dos grupos na sala. Essa estratégia de escolha é uma expectativa construída pelos alunos ao longo de sua história de participação conjunta. Uma aluna, no turno 32, evidencia como essa estratégia já é internalizada pelo grupo, lembrando à professora a direção que a escolha dos alunos deverá seguir naquela atividade de leitura.

A aluna Karina foi escolhida. Sua leitura foi entremeada por intervençóes da professora, como indicam os turnos 36 a 42. A professora interrompeu sua leitura para chamar a atenção da turma e para corrigir a pronúncia da palavra Áustria. A leitura de Karina foi avaliada positivamente pela professora, uma açáo muito utilizada por ela após a leitura oral, o que evidencia o objetivo predominante da atividade de leitura oral nessa sala de aula: avaliar as habilidades de fluência e, nesse processo, corrigir cada aluno em relação à pronúncia de certas palavras e à entonação.

No turno 43, inicia-se a discussáo do texto lido, mas a professora desconsidera as duas perguntas que o livro propóe: "de que tipo de música você gosta? Diga o nome de uma música que você gosta”. Ela inicia a discussão com base no mapa que ilustra o texto. Nesse sentido, a dinâmica discursiva é constituída primeiramente em torno das ilustraçóes do texto, seguida da discussáo do próprio texto.

A estrutura da dinâmica discursiva é variada. Observamos cadeias de discussão não triádicas, em que os alunos introduzem temas relacionados à pergunta da professora mas expandem a discussão, ou formulam perguntas buscando informações adicionais. Por exemplo, entre os turnos 47 e 60, há uma discussáo sobre a distância entre a Áustria e o Brasil, provocada pela pergunta da professora, ao final do turno 47: "vocês acham que a Áustria é longe do Brasil?" Ainda que respondida já no turno 48, a professora continua a discussáo, perguntando no turno 49 sobre o "que tem no meio". Uma das alunas responde ao que foi solicitado no turno 52, mas os alunos introduzem outros elementos em suas respostas - o meio de transporte e o tempo de viagem. A professora contempla esses temas e sustenta a discussão com os alunos. Apesar de haver estruturas de Iniciação-Resposta-Avaliação (IRA) (Mehan, 1979), elas configuram cadeias de interação e não tríades do tipo IRA, e são mais abertas por contemplar temas não totalmente previstos. Nesse sentido, aparece a tensão entre o discurso de autoridade e o internamente persuasivo (Bakhtin, 1981), pois ao mesmo tempo que os alunos têm espaço para manifestar suas interpretaçóes e introduzir temas à discussão, a professora mantém o foco na discussão de aspectos ligados à ilustraçáo.

Em vários turnos da professora, percebem-se, no mínimo, duas funções distintas relacionadas àquelas encontradas por Mehan (op.cit.): primeiro a professora ava- 
lia a resposta ou a iniciação do aluno e, em seguida, inicia novamente (por exemplo, turnos 43, 45, 47, 49 e 53). Além disso, numa mesma iniciação, percebemos outras funçôes, como no turno 47: confirmar a resposta dos alunos; recuperar informaçóes do contexto interacional, constituídas em aulas anteriores; avaliar a leitura da aluna e iniciar uma nova sequência: "Como eu falei para vocês, ele foi um dos maiores compositores do mundo, mas isso há muito tempo atrás. Vocês acham que a Áustria é longe do Brasil?" O discurso da professora, nesse turno, é um exemplo da complexidade que caracteriza a dinâmica discursiva da sala de aula, pois, em um mesmo turno, a professora utiliza seu discurso para avaliar, informar e solicitar. Consideramos que a análise da ocorrência do padrão IRA, como uma estrutura fechada, não possibilita a explicitaçáo dessa complexidade, por não ser a única forma de estruturaçáo da dinâmica discursiva nessa sala de aula.

Uma das razões para que o discurso não adquira, predominantemente, as formas triádicas, características do padrão IRA, pode ser o fato de os alunos intervirem frequentemente com observaçóes e perguntas que são muitas vezes contempladas pela professora. Desse modo, as tríades não se realizam da maneira como foram analisadas por Mehan (op.cit.), mas entremeadas por observaçóes dos alunos, que são contempladas pela professora sempre que a perspectiva referencial deles coincide com a sua, como se observa nos turnos 53, 55 e 57.

Por que a dinâmica discursiva nessa sala de aula tem essa flexibilidade? Levantei uma hipótese: o fato de os alunos serem crianças pode ser um dos fatores condicionantes dessa dinâmica. Nessa faixa etária, eles ainda não aprenderam a regra da cultura escolar - de falar um de cada vez - embora seja reiterada pela professora em todos os eventos. Outra hipótese está relacionada ao fato de a professora ter conduzido a discussáo do texto sem considerar as duas perguntas propostas pelo livro, ou seja, a discussão foi bem mais abrangente, incluindo um diálogo com as ilustraçóes do texto, para o qual não havia perguntas pré-definidas. Pode ser que na discussão de conceitos gramaticais ou matemáticos, por exemplo, a dinâmica seja mais rígida e mais fechada. Talvez as intervençóes dos alunos não sejam tấo frequentes e as respostas táo variadas. Em pesquisa anterior, encontramos maior rigidez e menor participação dos alunos em discussóes sobre a ortografia (Macedo, 1998).

Tomando como referência o conceito de polifonia de Bakhtin (1995), percebe-se, na dinâmica discursiva de todo o evento, as diferentes vozes que circulam na realização da atividade proposta. O livro didático é uma voz presente, mas é apenas uma dentre as muitas vozes que constituíram todo o desenvolvimento da temática proposta pelo livro. Essa voz mescla-se com a voz da professora, que, em alguns turnos, assume 
a voz do livro didático (43, 47, 61 e 77), mas na maior parte dos turnos sua voz predomina, em razão dos conhecimentos da vida de Mozart. A maior parte do que foi discutido náo está presente no texto do livro, é resultado das discussóes do mapa e da foto do compositor, discussóes essas mediadas pelas perguntas dos alunos. A professora discute as ilustraçóes veiculadas, enfatizando a época a que se referem: "É, na época que ele viveu, na época que ele viveu, todas as pessoas, até as crianças, usavam peruca no cabelo" (turnos 69, 71 e 75). Essa discussão possibilita que os alunos comparem seus valores e costumes com os de antigamente. A exploração do mapa, apresentado no LD para localizar a Áustria em relação ao Brasil, propicia que os alunos, de forma contextualizada, produzam conhecimentos específicos dos processos de letramento em aulas de geografia, como, por exemplo, a leitura e interpretação de mapas.

Nesse processo, as vozes dos alunos estão presentes nas perguntas que introduzem temas novos ou pedem explicaçóes adicionais (turnos 50, 70 e 78), reelaborando respostas dadas pela professora em turnos anteriores (turno 58) e fazendo comentários com base em seus conhecimentos prévios (turno 62). A dinâmica de interaçóes conduzida pela professora é aberta o suficiente para que todas essas intervençóes, em que os alunos trazem seu horizonte conceitual (Bakhtin,1929/1995), suas "vozes" sejam, de alguma forma, contempladas no discurso que está sendo construído. A ironia presente na voz de Robert (turno 62), evidencia o uso de um discurso internamente persuasivo (Bakhtin, 1981) por parte dos alunos, tencionando com o discurso de autoridade da professora, que não aceita interpretação diferente daquela autorizada por ela (turno 63).

O discurso de autoridade também está presente nos momentos em que ela tenta controlar a disciplina do grupo. Nos turnos 37 e 61, ela chama a atenção dos alunos pedindo silêncio, sendo bastante enfática com dois que estavam desatentos (turno 61). A atitude de ficar de frente para a turma e de enunciar a palavra pronto também é um mecanismo de controle do comportamento, utilizado em todas as aulas filmadas. Nessa aula, a atitude ocorre no turno 31, em que a professora sinaliza que a leitura oral irá começar.

As intervenções da professora também buscam motivar os alunos para a participação nos eventos seguintes, criando um clima de suspense ou de mistério como se observa no turno 81 .

As análises dessa aula e dessa sequência discursiva enfatizam aspectos característicos das práticas de letramento escolar recorrentes na maior parte das aulas em que o livro didático esteve presente nesta turma. Leitura silenciosa e oral sáo as primeiras açóes realizadas, sempre da mesma forma, com os textos do livro, ainda que não sugeridas explicitamente pelo material. É importante notar que as discussóes desses 
textos não ocorreram segundo a proposta do livro, pois o grupo constrói um processo de interpretação do texto com base nas perguntas dos alunos e da professora. Torna-se fundamental, ainda, considerar o papel das ilustrações no processo de construção da leitura. Assim como no primeiro dia de uso do LD, a ilustração ocupou papel central, sendo mais discutida do que o próprio texto. Conforme analisado na aula anterior, nossa hipótese é de que a natureza e a qualidade dos textos do livro didático não possibilitam discussóes aprofundadas. Discuti-los após as ilustraçóes seria incorrer em repetiçóes, pois os debates foram bastante ampliados, em razão das ilustraçóes. Essa não é a perspectiva do material didático, uma vez que não há, no livro, nas aulas em que foi utilizado, nenhuma proposta para trabalhar com as ilustraçóes.

\section{CONSIDERAÇÕES FINAIS}

Neste artigo analisei a constituição de práticas de letramento, mediadas por um livro didático de português a partir de diferentes tipos de análises, numa perspectiva contrastiva (Green, Dixon e Zaharlick, 2001). Desse modo, ao mapear as atividades propostas no livro e as açóes construídas em sala de aula, pudemos contrastar as diferenças entre o que é proposto e prescrito pelo LD e a forma como esse recurso é apropriado em sala de aula. Além do mapeamento, analisei o discurso produzido nas interaçóes entre alunos e professora em duas aulas em que o LD foi utilizado. Essas análises confirmam que esse recurso é reconstruído pela professora de acordo com as demandas da própria prática, ou com os dispositivos que constituem seu "saber-fazer", o que faz com que a sequência do livro didático seja alterada para adequar-se à prática da professora. O seu uso, portanto, não é linear.

A análise da dinâmica discursiva, nessa sala de aula, permite afirmar que se trata de um processo dinâmico e complexo, em que diferentes padróes discursivos são construídos pelos participantes. O padrão IRA, mapeado e interpretado por Mehan (1979), está presente, mas não assume prioritariamente uma estrutura triádica. $\mathrm{O}$ que constatamos foi a presença de cadeias discursivas de interaçáo, como as encontradas por Mortimer e Scott (2003), nas quais o discurso da professora tem como perspectiva garantir a fluência das discussóes em sala de aula. Os alunos constroem sua participaçáo numa relaçáo dialógica com a professora e com o livro didático, por meio de diferentes estratégias discursivas, tais como: iniciar turnos de fala, solicitar informaçóes, avaliar o desempenho de colegas, perguntar para esclarecer dúvidas e responder às perguntas da professora. Esse processo é construído numa tensão entre discurso de autoridade e discurso internamente persuasivo, apontados por Bakhtin (1981) como as duas dimensóes do discurso, materializadas no que Wertsch (1991) denominou "tensão irredutível". 


\section{REFERÊNCIAS BIBLIOGRÁFICAS}

ALBUQUERQUE, E. B. C. Apropriações de propostas oficiais de ensino de leitura por professores: o caso do Recife. 2002. 361 f. Tese (Doutorado em Educação). - Faculdade de Educação da Universidade Federal de Minas Gerais, Belo Horizonte.

ARAÚJO, M. J. G. Práticas de leitura na escola e nas famílias em meios populares. 1999. Tese (Mestrado em Educação) - Faculdade de Educação da Universidade Federal de Minas Gerais, Belo Horizonte.

BAKHTIN, Mikhail. The Dialogic imagination. Austin: University of Texas Press, 1981.

7.ed. São Paulo: Hucitec, 1995. . Marxismo e filosofia da linguagem.

BATISTA, A. A. G. Um objeto variável e instável: textos, impressos e livros didáticos. In: ABREU, M. (Org.). Leitura, história e história da leitura. Campinas: Mercado de Letras, 1999.

COLINS, E.; GREEN, J. Learning in classroom settings: making or breaking a culture. In: MARSHALL, H. (Ed.). Redefining student learning: roots of educational reestructuring. Norwood: Ablex, 1992. p. 59-85.

FERREIRO, Emília. Com todas as letras. São Paulo: Mercado de Letras, 1993.

FERREIRO, Emília; TEBEROSKY, A . A Psicogênese da língua escrita. 4.ed. Porto Alegre: Artes Médicas, 1991.

GREEN, J.; MEYER, L. A. The Embeddedness of reading in classroom life. In: BAKER, C.; LUKE, A. Towards a critical sociology of reading pedagogy. Philadelphia: Jonh Benjamins, 1991. p.141-160. GREEN, J.; DIXON, C.; ZAHARLICK, A. Ethnography as a logic of inquiry. In: FLOOD, J. et al (Ed.). Handbook for research on teaching the English language arts. 2.ed. New Jersey: LEA, 2001.

GREEN, J.; WALLAT, C. Mapping instructional conversations: a sociolinguistics ethnography.
In: Ethnography and languages in educational settings. New Jersey: Ablex, 1981. p. 161-195

HEATH, S. B. Ways with words: language, life and work in communities and classrooms. Cambridge: Cambridge University Press, 1983. KLEIMAN, A. (Org.). Os Significados do letramento. Campinas: Mercado de Letras, 1995.

MACEDO, M. S. A. N. A Dinâmica discursiva na sala de aula e a apropriação da escrita. 1998. 188 f. Tese (Mestrado em Educação) - Faculdade de Educação da Universidade Federal de Minas Gerais, Belo Horizonte.

MACEDO, M. S. A. N.; MORTIMER, E. F.; GREEN, Judith L. A Constituição das interações em sala de aula e o uso do livro didático: análise de uma prática de letramento no primeiro ciclo. Revista Brasileira de Educação, n. 25, p. 18-29, jan./abr. 2004.

MEHAN, H. Learning lessons: the social organization of the classroom. Cambridge: Harvard University Press, 1979.

MORTIMER, E. F.; SCOTT, P. H. Meaning making in secondary science classroom. Maidenhead: Open University Press/McGraw Hill, 2003.

SOARES, M. Letramento: um tema em três gêneros. Belo Horizonte: Autêntica, 1998.

A Escolarização da literatura infantil e juvenil. In: EVANGELISTA, A. et al. (Org.). A Escolarização da leitura literária. Belo Horizonte: Autêntica, 1999. p. 17-48.

SPRADLEY, J. Participant observation. New York: Holt, Rinehart \& Winston, 1980.

STREET, B. Literacy in theory and practice. Cambridge: Cambridge University Press, 1984.

WERTSCH, J. Voces de la mente: un enfoque sóciocultural para el estudio de la acción mediada. Madrid: Visor, 1991.

Recebido em: fevereiro 2009

Aprovado para publicação em: fevereiro 2009 